\title{
Crítica de mídia, sucesso de escândalo e narrativa política no Brasil hoje
}

\section{Media criticism, succès de scandale and political narrative in Brazil today}

Lígia Lana ${ }^{1}$ 


\section{Resumo}

Este trabalho reconstrói, pela ótica da crítica de mídia, narrativas políticas no Brasil, entre o final de 2018 e meados de 2019. Trata-se de uma revisão de textos publicados por articulistas e críticos de televisão na mídia brasileira. O quadro teórico é orientado pelos conceitos de sucesso de escândalo e entretenimento político, e a metodologia estabelece três operadores analíticos - celebridades, redes sociais e metacrítica. As conclusões do trabalho discutem as semelhanças entre a cultura da celebridade e a narrativa política; as transformações, trazidas pela internet, nas narrativas políticas; e o papel social da mídia na crítica dos processos políticos hoje.

Palavras-chave

Sucesso de escândalo, entretenimento político, crítica de mídia.

\section{Abstract}

From the perspective of media criticism, this article reconstructs political narratives between the end of 2018 and the middle of 2019 . The research is a review of texts published by journalists and television criticism in the Brazilian media. The theoretical framework is guided by the concepts succès de scandale and political entertainment, and the methodology establishes three analytical operators - celebrities, social media and metacritical. The conclusions discuss the similarities between celebrity culture and political narrative; the transformations, brought by the Internet, in political narratives; the social role of the media to criticize political processes today.

\section{Keywords}

Succès de scandale, political entertainment, media criticism. 
Em 2016, Donald Trump se elegeu presidente dos Estados Unidos com o Príncipe da Escuridão - como adversários apelidaram Roger Stone - sendo um dos maiores articuladores da vitória republicana. O documentário Get Me Roger Stone (2017), produzido pela Netflix, traz questões interessantes para pensar a relação entre a mídia popular e a política hoje. O filme elucida, em entrevistas com jornalistas, políticos e com o próprio personagem, as estratégias de Stone: associação de política e entretenimento e criação de narrativas que buscam a visibilidade a qualquer preço. Apresentando-se como um agent provocateur, Roger Stone explica: "É melhor ser infame do que nunca ser famoso", em alusão a conhecidos processos de formação de celebridades, em que a desmoralização se converte em moeda de troca na conquista do capital de visibilidade ${ }^{2}$. Roger Stone se orgulha de ter criado histórias falsas - como a de Barack Obama não ter nascido nos Estados Unidos - porque, para ele, "política é show business para pessoas feias. [...] você acha que os eleitores não sofisticados sabem diferenciar entretenimento de política?" (GET..., 2017).

Mais do que o registro de um personagem da história norte-americana, Get Me Roger Stone expõe um retrato desconcertante de nosso tempo. As narrativas políticas tornaram-se reféns de formas midiáticas construídas pela exacerbação da indignação, do ressentimento, do racismo, da xenofobia, da conspiração e da mentira ${ }^{3}$. O sensacionalismo, antes restrito a determinados produtos e espaços da mídia, parece ter se convertido em modalidade corriqueira da narrativa política, que hoje é produzida facilmente pelas pessoas comuns na internet através de memes, correntes e vídeos virais.

Esse cenário pode ser observado hoje também no Brasil. A consensual ideia da polarização, caracterizada por hostilidade, tendências antidemocráticas e irresponsabilidade, enraizadas na cultura brasileira, sugere a necessidade de 
aprofundar a reflexão em torno das narrativas políticas hoje ${ }^{4}$. A crítica de mídia tem sido um lugar privilegiado para isso. Articulistas, críticos de televisão e colunistas sociais vêm registrando, em jornais impressos e em blogs com grande visibilidade, observações a respeito do assunto. Especialmente durante as eleições de 2018, em que a campanha suscitou o aumento da auto-observação (com os candidatos fazendo uso da mídia), a crítica produzida cotidianamente vem trazendo um material precioso para pensar a relação entre entretenimento, celebridade, escândalo e política.

Antes de mais nada, é preciso lembrar que os candidatos que disputaram o segundo turno das eleições presidenciais em 2018, Jair Bolsonaro e Fernando Haddad, não se enfrentaram em nenhum debate televisivo - mesmo sendo realizado um número recorde de debates nesta eleição, sete no total, superando apenas 1989, quando ocorreram seis (STYCER, 2018d). A três dias do primeiro turno, enquanto a Globo realizava, ao vivo, o último debate com os candidatos, a Record exibia uma entrevista gravada com o futuro presidente, que recebera alta médica depois do atentado em Juiz de Fora, onde, durante um ato de campanha, sofreu uma facada. A data das eleições se aproximava - e seria natural para a democracia que a população se informasse, através dos debates, para decidir em quem confiar seu voto. Na Rede Record, o mais importante, contudo, era a curiosidade pela recuperação de Bolsonaro, em um tipo de entretenimento político conhecido pelos telespectadores, que já haviam acompanhado as participações do então deputado no Superpop, CQC e Pânico (STYCER, 2018b).

A decisão da Record foi comercialmente acertada: segundo dados do Ibope, o Jornal da Record "registrou números superiores à sua média habitual e deixou a emissora em segundo lugar, à frente do SBT, o que não costuma ocorrer neste horário" (STYCER, 2018e). Assim, apesar de Patrícia Kogut (2018) anunciar o aumento da audiência da Globo durante a cobertura eleitoral, parece que a Record foi a emissora que mais capitalizou naquele período. 
O expressivo número de debates no primeiro turno contrastou com a inexistência de debates no segundo, algo inédito. A crítica de TV registrou, dia a dia, seu estranhamento com a não realização do debate final da Rede Globo. Como discute Jessé Souza (2017, p. 272), "sem a concorrência de televisões públicas como no contexto europeu", a Globo cumpre, há décadas, o papel de articulador de uma suposta esfera pública, "produzida e maquiada artificialmente". Isso sugere, segundo Serelle e Soares (2019), uma quebra na arraigada tradição do debate da Globo, que, diante das mídias digitais, mostrou-se dispensável na decisão sobre o voto.

Nas eleições de 2018, a contribuição da Rede Globo para o debate público com os candidatos resumiu-se a cinco entrevistas, que foram descritas pela crítica de mídia como "interrogatórios", com "enorme repercussão negativa".

Os encontros lembraram mais debates, duelos ou interrogatórios, com a dupla de telejornal adotando postura agressiva e inquisidora. Em algumas, como diante de Ciro, a dupla do JN ocupou mais de $40 \%$ do tempo. As entrevistas foram muito pouco esclarecedoras, incômodas e, no limite, inúteis mesmo. (STYCER, 2018d)

As emissoras paulistas, normalmente as lanterninhas no Ibope SBT, Record, Band e Rede TV! - e suas principais faces públicas - Sílvio Santos, Ana Hickmann, Luciana Gimenez, José Luís Datena e Amaury Jr. - alinharamse, desde o período eleitoral, ao bolsonarismo. Maurício Stycer registrou, em 1 de novembro de 2018, a entrevista exclusiva do novo presidente da República à Record e, dois meses depois, sumarizou o favoritismo da emissora na preferência do chefe do executivo. No primeiro dia do novo governo, a Record já havia exibido cinco entrevistas exclusivas, seguida pela Band, que transmitiu três - duas delas com a estrela da casa, José Luís Datena, que teve acesso à intimidade do leito hospitalar do candidato. A Rede TV! estava em terceiro lugar, com duas entrevistas. 
Como insistiu bastante Maurício Stycer (2018e), a Record contribuiu com uma "ajuda para Bolsonaro", prejudicando "o interesse público", que, para retomar a definição de Jessé Souza, antes era produzida de maneira maquiada e artificial pela Globo, mas que, pelo menos, era feito. No dia seguinte à vitória, o presidente eleito concedeu entrevistas às cinco maiores emissoras, mas a primeira e mais longa foi à Record, única a ser elogiada por seu "jornalismo isento" (STYCER, 2018a).

Houve privilégios para alguns, mas registrou-se também desvantagens para outros: na rádio Guaíba, Juremir Machado foi impedido de fazer perguntas ao então candidato; na entrevista à Globo, depois de eleito, o presidente anunciou o fim do jornal Folha de S.Paulo; nas redes sociais, a jornalista Patrícia Campos Mello foi alvo de centenas de ameaças de morte em razão de uma reportagem investigativa sobre ilegalidades na campanha eleitoral de Bolsonaro.

Buscando pelo assunto em grandes portais e jornais de circulação nacional, foram encontrados cerca de trinta textos. Desse material, apenas artigos, matérias e reportagens que tratassem exclusivamente do uso da linguagem pelo governo federal foram coletados para a análise: quer dizer, não foram selecionados textos que trouxessem, por exemplo, críticas a decisões ou articulações políticas. No tratamento dos dados, uma análise prévia de conteúdo revelou a existência de três temas relevantes em vinte textos, que foram utilizados como operadores analíticos da pesquisa, apresentada a seguir.

\section{Apoio e reprovação de celebridades}

A crítica de mídia buscou contrastar apoio e reprovação de celebridades ao atual presidente. Em linhas gerais, os articulistas apontaram uma polarização entre o apoio das celebridades paulistas relacionadas a emissoras paulistanas e a reprovação das celebridades cariocas relacionadas à Globo. Durante as eleições de 2018, houve muito engajamento das celebridades da Rede Globo nas mobilizações Ele Não e Vira Voto. Por outro lado, especialmente após as eleições, famosos ligados à mídia paulista apoiaram abertamente Jair Bolsonaro a circulação de um vídeo da apresentadora Luciana Gimenez parabenizando 
o candidato do PSL pela vitória antes do resultado das eleições de 2018 foi um episódio marcante.

Ainda durante o período eleitoral, dois casos tratados pela crítica de mídia foram interessantes. O primeiro é sobre a atriz Regina Duarte, que se alinhou ao bloco de apoio a Bolsonaro. O crítico de TV Nilson Xavier (2018) perguntou: "Malu Mulher votaria em Bolsonaro?". Analisando uma entrevista de Regina ao jornal Estado de S.Paulo, Xavier retomou algumas declarações da atriz: "Quando conheci Bolsonaro encontrei um cara doce, um homem dos anos 1950 [...] um jeito masculino" (XAVIER, 2018). Além da entrevista, Regina engajou-se na campanha presidencial divulgando fotografias no Instagram e justificando arroubos machistas, racistas e homofóbicos de Jair Bolsonaro. "São imagens montadas, pois mostram a reação dele, mas não a de quem provocou a reação. É unilateral". Nilson Xavier então contrapôs o posicionamento da atriz à personagem Malu.

\footnotetext{
Malu era uma mulher de ideias liberais, que se separava do marido machista, rompia com os pais castradores e ia à luta pelos seus direitos, de mãe, cidadã, mulher. O programa fez sucesso por abordar de forma corajosa e inédita em nossa TV questões muito delicadas para uma época em que o país vivia sob o jugo da ditadura militar - feminismo, sexo, orgasmo, aborto, virgindade, métodos anticoncepcionais, gravidez indesejada, violência doméstica, etc. (XAVIER, 2018)
}

Malu era socióloga, e Ruth Cardoso, amiga de Regina, contribuiu para a criação da personagem, uma tentativa de "quebrar o estigma de 'Namoradinha do Brasil', que perseguia Regina por causa de seus papéis de mocinha romântica em novelas". O crítico de TV concluiu: "Questiono se Malu, que tanto lutou pela libertação da mulher do jugo machista e patriarcal, também defenderia e votaria em Bolsonaro em 2018 - como sua intérprete" (XAVIER, 2018).

O segundo caso é sobre a cantora Anitta, que propiciou discussão sobre questões relacionadas às lutas identitárias. Em setembro de 2018, a cantora foi muito criticada por seguir uma amiga que declarava voto em Jair Bolsonaro. Seu principal fã-clube, Central Anitta, anunciou que "devido aos últimos acontecimentos" faria uma "pausa até o momento em que Anitta se pronuncie 
sobre seguir um perfil que apoia o candidato que é contra as minorias, público-alvo da cantora. Estamos tristes e queremos respostas", texto citado pelo blogueiro Chico Barney (2018a).

\begin{abstract}
O debate político deste ano está em um nível tão intenso e profundo que até as relações apaixonadas entre fãs e ídolos não estão passando incólumes. Resta saber se Anitta terá capital carismático para superar esse momento de grande crise - ou se mudará drasticamente o conteúdo de seu repertório. (BARNEY, 2018a)
\end{abstract}

Alguns dias depois, Anitta declarou que apoiava o movimento Ele Não. Antes desse caso, o organizador do Miss Bumbum, Cacau Oliver, divulgara uma nota anunciando o apoio das doze postulantes do título de 2018 a Jair Bolsonaro. Entre elas, havia duas transexuais que, conforme noticiou Chico Barney (2018b), não apoiavam o candidato, o que fez com que a organização do Miss Bumbum retificasse a informação enviada à imprensa, promovendo também o debate em torno dos posicionamentos de Jair Bolsonaro a respeito das lutas por reconhecimento.

Em 2019, as relações do governo com as celebridades permaneceram observadas pela crítica de mídia. Em abril, a colunista Mônica Bergamo anunciou os bastidores de um jantar em São Paulo com os ministros Guedes e Moro e

a atriz Regina Duarte, os cantores sertanejos Zezé Di Camargo e Jorge, da dupla Jorge \& Mateus, as apresentadoras Ana Hickmann e Luciana Gimenez e o jogador Kaká. [...] Os convidados fizeram muitas selfies com o ministro Moro, o mais popular do governo. A mulher do ex-magistrado, Rosângela Moro, também fez selfie com os artistas e postou em suas redes sociais. (BERGAMO, 2019)

Em maio de 2019, o site Meio \& Mensagem noticiou que o governo faria ações de merchandising sobre a reforma da previdência5. "Além de Luciana Gimenez e Ratinho, estão escalados [...] os apresentadores Milton Neves e José Luiz Datena (Band), Rodrigo Faro, Ana Hickmann e Renata Alves (Record)" (SACCHITIELLO, 2019). 
Segundo a matéria, as estrelas da Rede Globo teriam ficado de fora da campanha, pois a emissora veda que seus apresentadores façam merchandising.

Com a maioria das celebridades brasileiras - vinculadas à Rede Globo não aprovando a atual administração federal, parece haver uma estratégia natural do governo para se aproximar dos famosos que o apoiam. A trajetória e o perfil dessas celebridades podem ajudar a compreender esse aspecto da narrativa bolsonarista. Em pesquisas anteriores, analisei duas dessas figuras públicas: José Luís Datena (LANA, 2009) e Luciana Gimenez (LANA, 2013). Além de pertencerem ao eixo paulista da mídia, ambos possuem popularidade menor quando comparados a outros apresentadores - angariando menos rendimentos financeiros. Eliana, Xuxa e Angélica são mais bem pagas que Luciana Gimenez, assim como Faustão, Gugu e Luciano Huck ganham mais do que Datena.

José Luís Datena e Luciana Gimenez atuam em busca do sucesso de escândalo, termo de Ari Adut (2008) para descrever acontecimentos negativos que ganham notoriedade e se tornam socialmente relevantes, alterando o curso da vida social. Nos programas de Datena e Gimenez, o mais importante é aumentar a audiência, independentemente da boa preparação do conteúdo exibido. "Para aqueles que trabalham em setores altamente competitivos e com baixo nível de consenso normativo, onde ser notado por multidões é difícil e essencial para o sucesso, qualquer publicidade, independente da forma obtida, pode ser boa"6 (ADUT, 2008, p. 33, tradução nossa). O sucesso de escândalo possui efeitos imprevisíveis. No caso de Kate Moss, por exemplo, o uso de cocaína foi um escândalo que fortaleceu sua imagem pública, tornando-a uma inspiração para os dependentes químicos (ADUT, 2008). Entretanto, Adut indica que nem sempre os efeitos do sucesso de escândalo são positivos, já que podem macular a imagem dos envolvidos.

Assim, cabe ainda indagar como a crítica de mídia vem percebendo a construção da notoriedade do atual presidente. Maurício Stycer (2018b) lembrou suas participações em Superpop, CQC e Pânico, aproximando seu processo 
de celebrização às estratégias de Roger Stone, mencionado na abertura deste artigo. As regras do método Roger Stone aproximam-se da noção de sucesso de escândalo: por exemplo, "Ataque, ataque, ataque - nunca defenda, não admita nada, negue tudo, parta para o contra-ataque" e "A única coisa pior na política do que estar errado é ser chato" (GET..., 2017). Algo semelhante ocorreu na exitosa criação da narrativa bolsonarista.

CQC e Superpop entre outros, lucravam (pontos no Ibope) com a exibição de ideias consideradas ultrajantes e não parou de repeti-las na TV. Apostou no papel de antissistema, reproduziu fake news (o "kit gay", por exemplo) e nunca fez questão de parecer bonzinho. Raramente foi confrontado nestes programas. E quando foi, o objetivo era apenas elevar a temperatura da polêmica, e não esclarecer qualquer coisa. Foi um casamento perfeito. (STYCER, 2018b)

Reinaldo Azevedo (2019b) definiu a estratégia como "marketing da rusticidade", que criava um personagem do tipo "homem do povo, que não se importa com códigos, regras, etiqueta". Azevedo se referia, na análise, aos trajes "escalafobéticos" usados pelo presidente recém-eleito para receber no Palácio da Alvorada ministros do governo. "Usava uma calça tactel azul, uma camiseta pirata do Palmeiras, um blazer que não combinava nem com uma coisa nem outra e chinelos modelo slide, que não só deixam os dedos à mostra como os projetam. O conjunto era a visão do inferno em matéria de estilo". Associando moda e democracia, Azevedo analisou a construção da visibilidade do presidente.

Ocorre que, na democracia de direito, a forma não é uma escolha, mas um princípio. É claro que aquela mistureba hedionda não é causa de nada. Na verdade, a composição escalafobética já é consequência de um pensamento torto sobre a ordem democrática e suas exigências decorosas. Bolsonaro é a encarnação do poder do povo. E o nosso povo é bem melhor do que aquilo. Não cumpre ao presidente da República sugerir que somos piores do que somos porque ele resolveu fazer marketing pessoal, expondo ao público uma combinação que nem errada consegue ser. (AZEVEDO, 2019b)

Entretanto, é preciso lembrar que o presidente foi eleito pelo povo, o que leva a uma reflexão sobre os significados da democracia em nosso país. Um dos 
entrevistados do documentário Get me Roger Stone afirmou: "Democracia é o processo de apelar à maioria". Na era das celebridades, a democracia parece ser definida, cada vez mais, pelas lógicas de visibilidade da mídia - que a celebridade sabe bem como manejar.

\section{Lógicas das redes sociais}

De acordo com os textos analisados, a internet é fundamental para esse modelo narrativo da democracia de entretenimento político. Nesse sentido, um fato importante, como mencionado antes, ocorreu durante as eleições, quando a jornalista Patrícia Campos Mello publicou suas investigações sobre o financiamento ilegal da campanha de Jair Bolsonaro, com o disparo em massa de mensagens pelo WhatsApp. Depois das eleições, o caso mais emblemático ocorreu no carnaval, quando o chefe do executivo divulgou no Twitter um vídeo pornográfico, seguido da indagação sobre o significado do termo golden shower. Os articulistas avaliam o uso das redes sociais tratando da obsessão do governo pelo sucesso de escândalo, da celebração da comunicação direta com seus apoiadores e da conquista da atenção do mundo, uma vez que possui um valioso capital de visibilidade.

Eliane Brum (2019) defendeu que a comunicação através da internet feita pelo atual governo "corrompe a democracia", ao invés de fortalecê-la, como argumentam os bolsonaristas ao enaltecerem o uso das redes sociais, que traria, segundo eles, uma comunicação direta com o povo. Brum retomou dois eventos ocorridos nos dois primeiros meses da nova administração - a demissão do ministro Gustavo Bebianno e a reprovação do nome de Ilona Szabó para integrar o Conselho Nacional de Política Criminal e Penitenciária, órgão do Ministério da Justiça - , revelando a estreita ligação entre postagens no Twitter e a condução da administração federal.

Bolsonaro tenta convencer que se mover pelos gritos dos bolsocrentes nas redes sociais é democracia. Não é. [...] O que Bolsonaro garante é apenas o desejo de um grupo capaz de fazer seus gritos ecoarem na internet, muitas vezes pelo uso de robôs. (BRUM, 2019) 
De acordo com Eliane Brum, o mais desconcertante é o governo acreditar que seus seguidores, sejam fãs, sejam robôs (os bots), que reproduzem e aplaudem postagens, representam, de fato, a maioria da população, ponto de vista compartilhado por Demétrio Magnoli (2019). Na internet, o governo de "extremistas [...] confunde os ecos de seus tuítes com a voz do povo" (MAGNOLI, 2019).

Fernando Gabeira (2019) definiu o Twitter como o sofá de Bolsonaro: "Os aliados aconselham Bolsonaro a deixar o Twitter. Parecem não ter percebido que o tuíte não se escreve sozinho. É apenas uma plataforma que pode ser usada com sensatez ou não. Tirar o Twitter é tirar o sofá". Gabeira associou o Twitter à divulgação das ideias "retrópicas" de Bolsonaro, que, segundo ele, seria a principal tendência do governo federal: a utopia de um passado inexistente. No sofá, descansando da difícil e complexa tarefa que é governar na prática, Bolsonaro "vai prosseguir na sua cruzada retrópica" (GABEIRA, 2019). A metáfora do sofá - móvel utilizado para o descanso e, também, para assistir à televisão ilustra o posicionamento de Roger Stone sobre o entretenimento político: não há problemas, na política, em estar errado ou falar mentiras; o ruim é ser chato, pois é preciso entreter a plateia.

Segundo os críticos, a provocadora narrativa bolsonarista na internet revelaria uma inabilidade para governar. Os articulistas apontam que o bolsonarismo parece mais à vontade na internet, entretendo a população.

Como analisam Márcio Serelle e Rosana Soares (2019, p. 4), esse novo tipo de entretenimento político tem fomentado o debate público no Brasil hoje: "as formas de entretenimento vinculadas à informação muitas vezes deslocada da mídia dominante são o substrato dos textos midiáticos que circulam nas redes sociais". Dessa maneira, a narrativa bolsonarista na internet utiliza o entretenimento, onde pode ocorrer a suspensão momentânea da realidade, com a criação de mundos imaginados. O entretenimento político fornece formas narrativas e "também a possibilidade de suspensão de uma realidade imediata para que se possa vivenciar um mundo à parte, onde operam produtivamente narrativas que não estão sob o jugo do factual" (SERELLE; SOARES, 2019, p. 18). 
Reinaldo Azevedo (2019a) caracterizou a "turma que passou a ter existência nas redes" com as eleições de 2018 como personagens de "um eterno 'Show de Truman'". Entretanto, ao contrário do inocente Truman, que não sabia que sua vida era vivida em um estúdio de televisão, os novos "parlamentares das redes" seriam mais perniciosos.

O que há de novo, neles, em essência? Nada! Vivemos, aqui e no mundo, a era do populismo eletrônico. Se a grei que dá os "likes" resolve dizer a seus parlamentares virtuais um "não", inclusive à reforma da Previdência, então é "não". [...] [Têm] na cabeça o quê? A maioria, nada! Eram, com raras exceções, especialistas bem-sucedidos na ofensa e na agressividade gratuitas nas redes. (AZEVEDO, 2019a)

No Twitter, o deputado Daniel Coelho (Cidadania-PE) expôs uma versão interessante para o fenômeno.

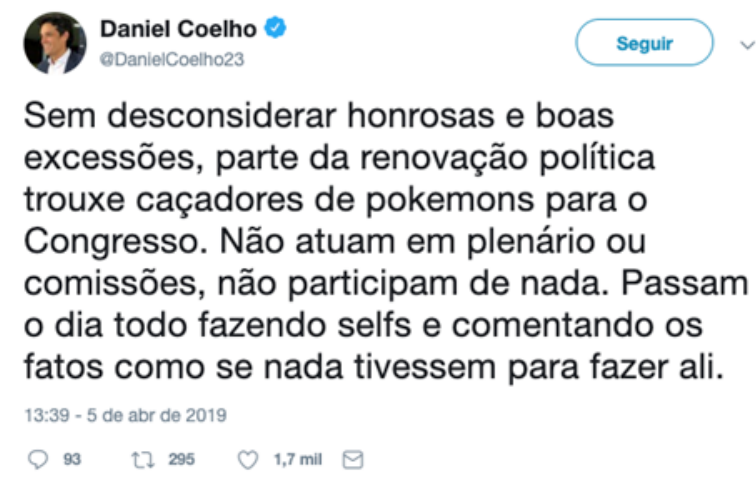

Figura 1: Postagem de Daniel Coelho no Twitter Fonte: Coelho (2019).

A definição "caçadores de pokemons" vai ao encontro de algo que a crítica de mídia vem mostrando sobre a narrativa bolsonarista: muita habilidade para aparecer na internet, mas pouca ou nenhuma capacidade para desenvolver as atividades para as quais foram eleitos. Conforme Reinaldo Azevedo (2019a), as redes sociais estariam demonstrando que Bolsonaro ignora que o "objetivo não é vencer as eleições, é governar [...]. E isso Bolsonaro não sabe fazer. $E$, 
em certa medida, não quer". Parece, portanto, que, segundo a crítica de mídia, a nova política brasileira seria mais um discurso do que, de fato, uma real transformação para a administração do país.

\section{Crítica/metacrítica}

Por fim, muitos textos da crítica de mídia avaliaram as análises que a mídia fez da narrativa bolsonarista, o que leva a pensar sobre o lugar da crítica/metacrítica. Durante as eleições, a chefe de redação da Rede Record pediu demissão por não concordar com a interferência da cúpula da emissora na condução do noticiário da época, que não poderia ser crítico ao candidato. A demissão motivou que funcionários do setor de jornalismo de todo o grupo (TV, rádio e Portal R7) procurassem o sindicato dos jornalistas de São Paulo para denunciar a "pressão permanente da emissora" (SINDICATO..., 2018).

Também durante o período eleitoral, a HBO deixou de exibir o programa Last Week Tonight, que fazia críticas a Bolsonaro e Haddad - as mais ácidas ao futuro presidente. Segundo Maurício Stycer (2018c), o apresentador de Last Week Tonight teria dito: "Qualquer coisa é melhor que Bolsonaro. O Lula diet é melhor, Homem Aranha é melhor". A crítica de mídia registrou o ocorrido, lembrando a derrubada do dispositivo eleitoral que pretendia proibir sátiras políticas durante as eleições. "Quem não quer ser satirizado, fica em casa, não se oferece para ocupar cargos políticos", postulou o relator do processo, ministro Alexandre de Moraes, em trecho divulgado por Maurício Stycer. "Querer evitar isso por meio de uma ilegítima intervenção estatal na liberdade de expressão é absolutamente inconstitucional" (STYCER, 2018c).

No início do governo, em 15 de janeiro de 2019, a Globo exibiu a "Vila Militar do Chaves", uma paródia feita pelo programa Tá no Ar, em que Marcelo Adnet representa o novo dono da vila do seu Barriga, um capitão, que "depois de anos de incompetência e má administração" veio "resolver esta questão". Reproduzindo a entonação do presidente recém-eleito e com texto muito crítico, "Bolsonaro de Adnet é o nosso melhor presidente desde Lula do Bussunda", afirmou Chico Barney (2019). 
Na análise, Barney retoma todas as paródias que a Globo fez dos últimos presidentes e conclui: "Com Jair Bolsonaro, Marcelo Adnet retoma a excelente tradição global de escrachar os chefe da nação. E em um alto nível que não era visto desde a fase áurea do Casseta \& Planeta. Não é pouca coisa" (BARNEY, 2019).

Parece haver, assim, uma constante tensão nos dispositivos críticos da narrativa política hoje. Os colunistas lembram a tradição de programas da Globo em parodiar os presidentes da República e, ao mesmo tempo, informam que algo que parecia improvável - a censura - voltou a acontecer no Brasil. No caso da HBO, tratou-se de autocensura, o que não deixa de ser uma informação relevante para a compreensão do processo eleitoral em 2018.

Demétrio Magnoli (2018) responsabilizou Trump e Bolsonaro "pelas centelhas de violência" ao cometerem "um crime chamado linguagem", "violando a sintaxe da democracia". Magnoli retoma termos usados pelos dois presidentes para se referir aos opositores: "inimigos do povo"; "guerra à imprensa" e os associa a outros: "ratos" (dos nazistas para judeus); "baratas" (em Ruanda, do regime hutu para os tutsis); "gusanos" (ou vermes, do castrismo para os dissidentes). Para Magnoli (2018), "as democracias começam a se envenenar quando os próprios governantes saltam o muro da linguagem, entrincheirando-se no fosso da 'guerra'. Aí, a pedagogia do ódio converte-se em doutrina estatal". As violentas tensões das narrativas políticas no contexto brasileiro ocorreram, de maneira semelhante, em outros lugares e momentos. A reflexão sobre a crítica de mídia, independentemente das particularidades dos países, leva a combater a indesejável degradação da linguagem, que impede o diálogo em um registro democrático.

\section{Considerações finais}

A crítica de mídia, divulgada em jornais e blogs de grande visibilidade, parece fornecer interessantes pistas para compreender as narrativas políticas em evidência hoje no cenário brasileiro. Descortinando, no dia a dia, a linguagem do governo, colunistas examinam, em consonância com a crítica acadêmica, aspectos da cultura midiática contemporânea. A consolidação da figura da celebridade no 
Brasil, por exemplo, é uma das explicações trazidas pelos articulistas, que coincide, em linhas gerais, com a percepção da pesquisa científica. A busca desenfreada pela fama e as engenhosas maneiras com que os indivíduos manipulam seu capital de visibilidade são explicitadas tanto pela crítica de mídia quanto pela pesquisa científica - cada qual com suas ferramentas, pressupostos e contribuições.

O assunto que mais parece inquietar a crítica de mídia é a participação das redes sociais nos processos decisórios da democracia. As novas possibilidades de produzir conteúdo através das mídias digitais colocam em tensão as formas tradicionais das narrativas políticas. O mundo imaginado por memes, correntes de mensagens e vídeos virais cria uma aura de entretenimento e a necessidade de constante provocação, que passam a direcionar a discussão de assuntos sérios, transformando os processos deliberativos.

A mídia possui a prerrogativa de "incluir publicamente", quer dizer, garantir publicidade para fatos, versões e acontecimentos. Por isso, conforme Ari Adut, jornalistas tendem a sobrevalorizar o papel da mídia na construção de escândalos políticos - e, por que não dizer, na condução de processos políticos de forma geral. Quando jornalistas passam a avaliar sua participação na esfera política, "seja se autoadulando como combatentes destemidos da corrupção, seja se autoflagelando como corruptores da moral pública, eles estão simplesmente confirmando seu suposto poder social e relevância, quiçá se entregando ao autoengrandecimento"7 (ADUT, 2008, p. 77, tradução nossa). A participação da mídia nas decisões políticas, para Adut, parece ser mais modesta. Práticas, hábitos e valores em curso na vida social são afetados pelas narrativas políticas na mídia, que devem ser compreendidas de maneira mais ampla, no seio da cultura e dos processos sociais.

Nesse sentido, os resultados deste trabalho sugerem que a crítica de mídia permite pensar sobre o papel das narrativas midiáticas no contexto político hoje. O controle social da mídia - que abrange a liberdade de imprensa e a criatividade para criar e disseminar correntes na internet - parece ser aqui um

$7 \quad$ No original: "whether self-adulating as the fearless fighters of corruption or self-flagellating as the corruptor of public morals, they are simply confirming their supposed social power and relevancy, if not indulging in self-aggrandizement". 
aspecto central. A disputa pela formação da opinião pública dos brasileiros, que, infelizmente, não possuem ainda acesso justo à educação de qualidade, ocorre em guerras de narrativas midiáticas, potencializadas pela polarização, provocação e desrespeito. A crítica de mídia, ao observar e desnaturalizar os modos como as narrativas políticas são constituídas, pode servir para aprimorar a compreensão das interferências da mídia na democracia no Brasil hoje.

\section{Referências}

ADUT, A. On scandal: moral disturbance in society, politics, and art. Nova York: Cambridge University Press, 2008.

AZEVEDO, R. Fim do show 2: objetivo não é vencer a eleição, é governar. Bolsonaro ignora. Blog do Reinaldo Azevedo, São Paulo, 2019a. Disponível em: https://bit.ly/2TTRQ0Y. Acesso em: 5 abr. 2019. (a)

AZEVEDO, R. Traje escalafobético de Bolsonaro é marketing ruim da simplicidade; não é que não entenda de moda: ele nada entende é de democracia. Blog do Reinaldo Azevedo, São Paulo, 2019b. Disponível em: https://bit.ly/2ACdnzg. Acesso em: 5 abr. 2019.

BARNEY, C. Fã-clube abandona Anitta após cantora seguir perfil que apoia Bolsonaro. Blog do Chico Barney, São Paulo, 2018a. Disponível em: https://bit.ly/2LJGmrm. Acesso em: 5 abr. 2019.

BARNEY, C. É melhor já ir se lamentando: Miss Bumbum Trans desiste de apoiar Bolsonaro. Blog do Chico Barney, São Paulo, 2018b. Disponível em: https://bit.ly/2AI1Tua. Acesso em: 5 abr. 2019. 
BARNEY, C. Bolsonaro de Adnet é o nosso melhor presidente desde Lula do Bussunda. Blog do Chico Barney, São Paulo, 2019. Disponível em: https://bit.ly/2LIK2cD. Acesso em: 5 abr. 2019.

BERGAMO, M. Guedes e Moro se reúnem com Kaká, Regina Duarte e Ana Hickman. Folha de S.Paulo, São Paulo, 2019. Disponível em: https://bit.ly/2Uu3ccq. Acesso em: 5 abr. 2019.

BRUM, E. Bolsonaro (des)governa o Brasil pelo Twitter. El País, Madri, 2019. Disponível em: https://bit.ly/2TsJEEA. Acesso em: 5 abr. 2019.

COELHO, D. Sem desconsiderar honrosas e boas excessões, parte da renovação política trouxe caçadores de pokemons para o Congresso. Não atuam em plenário ou comissões, não participam de nada. Passam o dia todo fazendo selfs e comentando os fatos como se nada tivessem para fazer ali. Brasília, DF, 5 abr. 2019. Twitter: @DanielCoelho23. Disponível em: https://bit.ly/2B9LyhR. Acesso em: 3 jun. 2019.

FREIRE FILHO, J. ; LANA, L. Pacto de visibilidade: mídia, celebridades e humilhação. Contracampo, Niterói, n. 30, p. 4-23, 2014.

GABEIRA, F. O Twitter como um sofá. Gabeira, Rio de Janeiro, 2019. Disponível em: https://bit.ly/2V8Agmo. Acesso em: 5 abr. 2019.

GET me Roger Stone. Direção: Dylan Bank, Daniel DiMauro e Morgan Pehme. Los Gatos: Netflix, 2017. 1 vídeo (92 min), son., col., HD.

KOGUT, P. 'Central das eleições' faz crescer a audiência da Globo News em 400\%. O Globo, Rio de Janeiro, 2018. Disponível em: https://glo.bo/32XDLj9. Acesso em: 3 jul. 2019. 
LANA, L. Para além do sensacionalismo: uma análise do telejornal Brasil Urgente. Rio de Janeiro: E-papers, 2009.

LANA, L. A vítima oportunista: a construção da celebridade Luciana Gimenez. Interseções, Rio de Janeiro, v. 15, p. 446-462, 2013

LIRA NETO, J. Príncipe da Escuridão é um dos responsáveis pela ascensão de Trump. Folha de S.Paulo, São Paulo, 2017. Disponível em: https://bit.ly/2OjZcH4. Acesso em: 3 jul. 2019.

MAGNOLI, D. Um crime chamado linguagem. Folha de S.Paulo, São Paulo, 2018. Disponível em: https://bit.ly/2pJ1ANI. Acesso em: 5 abr. 2019.

MAGNOLI, D. Retirada tática. Folha de S.Paulo, São Paulo, 2019. Disponível em: https://bit.ly/2w0gVsV. Acesso em: 5 abr. 2019.

SACCHITIELLO, B. Governo investe em merchandising pela Previdência. Meio \& Mensagem, São Paulo, 2019. Disponível em: https://bit.ly/2WuFae1. Acesso em: 3 jul. 2019.

SERELLE, M. Apresentação do dossiê "Polarizações". Rumores, São Paulo, v. 10, n. 19 , p. $4-7,2016$.

SERELLE, M.; SOARES, R. As novas formas do falso: entretenimento, desinformação e política nas redes digitais. In: COMPÓs, 28., 2019, Porto Alegre. Anais [...]. Porto Alegre: Compós.

SINDICATO denuncia pressões abusivas sobre os jornalistas da Rede Record. Sindicato dos jornalistas profissionais do estado de São Paulo, São Paulo, 2018. Disponível em: https://bit.ly/2EBg8ph. Acesso em: 4 jul. 2019. 
SOUZA, J. A elite do atraso: da escravidão à Lava Jato. Rio de Janeiro: Leya, 2017.

STYCER, M. Bolsonaro volta a privilegiar Record e dá exclusiva sobre convite a Moro. Blog do Maurício Stycer, São Paulo, 2018a. Disponível em: https://bit.ly/20fX7fi. Acesso em: 5 abr. 2019.

STYCER, M. Qual foi o papel de CQC, Superpop e Pânico na popularização de Bolsonaro. Blog do Maurício Stycer, São Paulo, 2018b. Disponível em: https://bit.ly/20j2muS. Acesso em: 5 abr. 2019.

STYCER, M. HBO não exibe no Brasil programa de humor que critica Bolsonaro e Haddad. Blog do Maurício Stycer, São Paulo, 2018c. Disponível em: https://bit.ly/2LKyJRg. Acesso em: 5 abr. 2019.

STYCER, M. Críticas a Globo, piadas de Daciolo e ajuda a Bolsonaro: a eleição na TV. Blog do Maurício Stycer, São Paulo, 2018d. Disponível em: https://bit.ly/2Mb3DkN. Acesso em: 5 abr. 2019.

STYCER, M. Record ajuda Bolsonaro ao exibir entrevista na hora do debate da Globo. Blog do Maurício Stycer, São Paulo, 2018e. Disponível em: https://bit.ly/356PXzN. Acesso em: 5 abr. 2019.

STYCER, M. Com cinco entrevistas, Record foi a favorita nos últimos três meses. Blog do Maurício Stycer, São Paulo, 2019. Disponível em: https://bit.ly/2oMonY6. Acesso em: 5 abr. 2019.

XAVIER, N. Malu Mulher votaria em Bolsonaro? Blog do Nilson Xavier, São Paulo, 2018. Disponível em: https://bit.ly/2IjxUN2. Acesso em: 5 abr. 2019. 